\title{
Criminologie
}

\section{Les événements d'octobre 1970 et l'administration de la justice pénale au Québec}

\section{José M. Rico}

Volume 13, numéro 2, 1980

Octobre 1970 : dix ans après

URI : https://id.erudit.org/iderudit/017123ar

DOI : https://doi.org/10.7202/017123ar

Aller au sommaire du numéro

Éditeur(s)

Les Presses de l'Université de Montréal

ISSN

0316-0041 (imprimé)

1492-1367 (numérique)

Découvrir la revue

Citer cet article

Rico, J. M. (1980). Les événements d'octobre 1970 et l'administration de la justice pénale au Québec. Criminologie, 13(2), 7-45.

https://doi.org/10.7202/017123ar d'utilisation que vous pouvez consulter en ligne.

https://apropos.erudit.org/fr/usagers/politique-dutilisation/ 


\section{LES EVÉNEMENTS D'OCTOBRE 1970 ET L'ADMINISTRATION DE LA JUSTICE PÉNALE AU QUÉBEC}

José M. Rico

\section{INTRODUCTION}

Les événements survenus au Québec en octobre 1970 ont surtout été analysés sous un angle politique. Les études de cette espèce ont montré comment, placés devant des défis inédits, les hommes publics, les dirigeants syndicaux, les intellectuels, les journalistes et, en général, l'opinion publique, peuvent se révéler sous des jours parfois insoupçonnés; elles fournissent également l'occasion d'une réflexion sans précédent sur la nature des malaises qui ont troublé la société québécoise de cette époque.

Dans la mesure où l'action violente des mouvements de libération du Québec supposait la violation de certains textes de loi, déclenchait de ce fait l'intervention des mécanismes officiels de réaction sociale et avait des répercussions importantes sur l'évolution de la politique criminelle canadienne et québécoise, ces événements se prêtaient aussi à une analyse criminologique. Celle-ci aurait pu se faire à un triple niveau. Sur le plan de la criminalité, l'examen des actes posés par le FLQ était d'un grand intérêt car ils se situaient dans le contexte de contestation violente propre aux années 60 et annonçaient la vague de terrorisme politique qui allait avoir lieu, au cours de la prochaine décennie, dans la plupart des pays occidentaux ${ }^{1}$. Au niveau des individus, l'étude aurait pu montrer les caractéristiques et les motivations des personnes qui, pour des considérations politiques, n'avaient pas hésité à utiliser la violence ${ }^{2}$. Enfin, l'analyse de la réaction sociale permettait de porter un jugement de valeur sur l'opportunité et l'efficacité de celle-ci.

C'est à l'étude de ce troisième aspect qu'est consacré le présent article. Son but essentiel est de montrer, à l'aide des faits les plus significatifs, les répercussions que les événements d'octo-

1. Cette approche est utilisée par Marc Laurendeau, Les Québécois violents, 2e édition, Montréal, Boréal Express, 1974.

2. L'ouvrage du Dr Gustave Morf, Le Terrorisme québécois (Montréal, les Editions de l'Homme, 1970) est un mauvais exemple de ce livre d'approche. 
bre 70 ont eues sur l'ensemble de l'administration de la justice québécoise.

\section{LES FAITS}

Les faits les plus significatifs reliés aux événements d'octobre 1970 remontent à 1963 ; leurs conséquences s'étendent jusqu'à nos jours. Nous les présentons sous une forme schématique :

1963

mars

Création du FLQ, mouvement révolutionnaire ayant pour but essentiel l'indépendance totale du Québec. Premières actions : barbouillage des édifices gouvernementaux, vols de dynamite et d'explosifs, attentats à la bombe.

avril Une bombe éclate au Centre de recrutement de l'armée à Montréal, causant la mort d'un gardien de nuit âgé de 65 ans.

novembre Georges Schoeters, considéré comme le père du FLQ est condamné à 10 ans de prison pour avoir placé des bombes dans les quartiers anglophones de Montréal.

1964

septembre Deux personnes sont tuées lors de l'attaque effectuée par un commando terroriste à l'International Firearms de Montréal. François Schirm et Édouard Guénette, membres du FLQ, sont déclarés coupables de cet attentat et condamnés à la peine de mort (leur sentence sera par la suite commuée en celle d'emprisonnement à vie).

1966

mai

Explosion d'une bombe à la manufacture de souliers La Grenade : mort d'une secrétaire (Mlle Thérèse Morin).

juillet Explosion d'une bombe à la manufacture Dominion Textile, causant la mort de Jean Corbo, membre du FLQ, qui la transportait.

1967

janvier

Pierre Vallières et Charles Gagnon, tous deux reliés aux activités du FLQ et inculpés pour ces deux attentats, sont extradés de New York.

Vallières est condamné à l'emprisonnement à vie pour homicide involontaire dans l'affaire La Grenade (sa peine sera réduite en appel à 30 mois de prison, en mai de la même année). 
juin A Montréal, le défilé de la Saint-Jean tourne à l'émeute.

septembre Gagnon est condamné à 2 ans de prison pour conspiration dans une tentative de vol dans un cinéma (un premier procès s'était terminé par le đésaccord des jurés). La Commission fédérale d'enquête McKenzie sur la sécurité nationale au Canada remet son rapport au gouvernement Trudeau (dans celui-ci on affirme que les deux principales menaces à la «sécurité nationale» sont le communisme international et le mouvement séparatiste au Québec).

1969

février Explosion d'une bombe à la Bourse de Montréal, faisant une trentaine de blessés dont trois grièvement. Arrestation à son domicile de Pierre-Paul Geoffroy, âgé de 26 ans et membre du FLQ, au moment où il fabriquait une bombe (il sera jugé quelques mois plus tard et, après avoir avoué sa participation à une centaine d'attentats à la dynamite, condamné à 124 fois l'emprisonnement à vie).

avril Gagnon est acquitté d'homicide involontaire dans l'affaire Corbo.

août Le procès contre Gagnon pour meurtre dans l'affaire La Grenade se termine par le désaccord des jurés (Gagnon sera acquitté en décembre et une accusation de sédition sera rejetée en novembre de la même année).

7 octobre L'armée canadienne occupe Montréal à la suite d'une grève illégale des policiers municipaux.

11 novembre Le ministre de la Justice du Québec, Me Rémi Paul, déclare qu'il y a au moins 3000 terroristes au Québec. M. Lucien Saulnier, président du Conseil exécutif de la ville de Montréal, parle à son tour d'importantes activités révolutionnaires à travers tout le Canada.

12 novembre Le Conseil municipal de Montréal adopte le règlement no 3926 interdisant les assemblées et les manifestations. Entre 1963 et 1969 , une vingtaine d'individus, accusés de crimes reliés aux activités du FLQ (attentats à la bombe, vols à main armée, possession d'explosifs, etc.) seront jugés et condamnés.

1970

mars

7 mai
Vallières est accusé de sédition pour son livre Nègres blancs d'Amérique (il sera libéré sous caution en mai).

Une semaine après les élections générales au Québec, le Cabinet fédéral forme un comité spécial dont la tâche est notamment de considérer * les mesures à 
prendre et les étapes à franchir » dans l'éventualité où la Loi sur les mesures de guerre serait proclamée.

juin

août

5 octobre

6 octobre

7 octobre

8 octobre

9 octobre

10 octobre
Un complot visant à l'enlèvement du consul des États-Unis à Montréal, M. Harrison Burgess, est mis à jour.

Une équipe de Radio-Canada rencontre, lors d'un voyage au Moyen-Orient, deux terroristes québécois qui s'entraînent à la guérilla avec des commandos palestiniens. Selon les renseignements obtenus, ils comptaient rentrer incessamment au pays pour $y$ pratiquer l'assassinat sélectif. On avance comme premières victimes MM. Trudeau, Bourassa et Drapeau.

Le diplomate britannique James Richard Cross est kidnappé à son domicile par quatre individus armés de mitraillettes et de revolvers. Quelques heures plus tard, la police découvre le premier communiqué du FLQ, dont les termes sont rendus publics, lors d'une conférence de presse, par le ministre québécois de la Justice. La cellule «Libération \$ menace d'exécuter $\mathbf{M}$. Cross si un certain nombre de conditions (parmi lesquelles figurent la diffusion du manifeste felquiste dans la presse et sur les ondes, la libération de 27 prisonniers politiques $»$ et leur transport aérien jusqu'en Algérie ou à Cuba) ne sont pas remplies dans un délai de 48 heures.

Le procès de Claude Morancy, accusé de 19 délits allant de la possession de dynamite au vol à main armée, est remis de 24 heures (des nouvelles remises lui seront accordées ultérieurement).

A Ottawa, les députés libéraux réclament le rétablissement de la peine de mort pour les meurtres perpétrés lors d'un enlèvement.

Ottawa autorise Radio-Canada à diffuser, sur les ondes de la télévision et de la radio d'État, le manifeste du FLQ. Un autre jeune felquiste, Robert Hudon, dont le nom figurait avec celui de Claude Morancy, sur la liste des \&prisonniers politiques * à libérer, est déclaré coupable de conspiration, de vol à main armée et de vol d'auto par un jury des assises et condamné à 20 ans de pénitencier.

Les stations radiophoniques de la métropole annoncent que l'armée canadienne est sur un pied d'alerte et que des mouvements de troupes sont signalés à divers endroits.

Le ministre de la Justice du Québec convoque une conférence de presse, au cours de laquelle il refuse de se plier aux exigences des ravisseurs de Cross. 
Il leur promet cependant, s'ils décidaient de se rendre, qu'ils bénéficieraient devant les tribunaux de \& toute la clémence qu'ils pourraient exercer » en prenant acte de tout geste humanitaire posé en vue d'épargner la vie du diplomate britannique. Quelques minutes seulement après cette déclaration, trois inconnus armés et masqués s'emparent à Montréal de M. Pierre Laporte, ministre provincial du Travail et de l'Immigration. La nouvelle de ce deuxième enlèvement cause l'effet d'une bombe et toutes les forces policières de la région métropolitaine sont mises en état d'alerte.

11 octobre La police effectue de nombreuses arrestations et perquisitions. Parmi les personnes arrêtées on compte des professeurs, des journalistes, des artistes et des avocats défenseurs des felquistes déjà capturés, dont Me Robert Lemieux. Tous les dossiers de ce dernier, a qui l'on refusera par la suite tout cautionnement, sont saisis par la police. A l'étranger, et partout au Canada, les journaux parlent des enlèvements en première page et sur un ton dramatique. M. Bourassa prononce une allocution radio-télévisée au cours de laquelle il demande aux ravisseurs d'entrer en communication avec le gouvernement pour fins de négociation. La police de Montréal et la Sûreté du Québec augmentent le nombre de leurs agents en service. Un porte-parole de la ville de Montréal révèle que les contribuabless devront payer environ $\$ 84000$ en temps supplémentaire aux policiers pour chaque jour où se poursuivront les recherches et les surveillances intensives. L'enquête relative aux enlèvements de MM. Cross et Laporte a été confiée à un groupe de policiers d'élite, l'escouade anti-terroriste, composée de policiers de la GRC, de la Sûreté du Québec et de la Police de Montréal.

12 octobre Environ 500 soldats de l'armée canadienne arrivent à Montréal. Une troisième cellule du FLQ (la cellule Nelson) donne signe de vie en adressant un communiqué à un poste de radio de Québec.

14 octobre Plusieurs noms bien connus de la scène québécoise (Claude Ryan, René Lévesque, Jacques Parizeau, Camille Laurin, Louis Laberge, Marcel Pepin, Yvon Charbonneau, Fernand Daoust, Alfred Rouleau, etc.) s'unissent pour donner leur appui au gouvernement Bourassa dans son intention de négocier un échange des deux otages détenus par le FLQ contre les terroristes emprisonnés.

15 octobre Le quotidien montrealais The Gazette dit avoir obtenu un rapport secret de la GRC dans lequel il est précise que le FLQ compte 22 cellules actives, totalisant 130 membres et 2000 sympathisants. Le Palais 
de Justice est évacué de toute urgence à la suite d'un faux appel à la bombe. Les cours de juridiction criminelle sont fermées à Montréal. Invoquant la Loi de la défense nationale, le Premier Ministre du Québec s'adresse au Gouvernement fédéral et demande le support de l'armée. Quelque 6000 soldats entrent presque immédiatement en action. Le directeur général de la Sûreté du Québec, M. Maurice St-Pierre, assume la direction d'environ 13000 policiers disséminés dans plus de 200 corps de police à travers le Québec. Le Comité exécutif du Conseil central des syndicats nationaux fait part de son appui inconditionnel à tous les objectifs du manifeste felquiste et ajoute que l'État a perdu le contrôle de la police. Les négociations avec les ravisseurs sont rompues. Plus de 3000 étudiants, rassemblés au centre sportif Paul-Sauvé de Montréal, acclament le FLQ. Au cours de cette assemblée, Pierre Vallières, Charles Gagnon, Michel Chartrand et Robert Lemieux prennent la parole.

16 octobre Le Premier Ministre du Canada reçoit des lettres du Premier Ministre du Québec et des autorités de la Ville de Montréal l'avisant de l'existence dans la province «d'un état d'insurrection appréhendée 》. Le Gouverneur en conseil approuve l'émission d'une proclamation en vertu de laquelle la Loi sur les mesures de guerre est décrétée dans tout le Canada. D'après cette loi, les pouvoirs de la police sont considérablement accrus et les juges ne peuvent plus accorder des cautionnements sans le consentement écrit du Procureur général de la province. Des arrestations et des perquisitions massives ont lieu pendant la journée. Plus de 12000 policiers et militaires effectuent 250 arrestations et 170 perquisitions. Parmi les premières victimes, on trouve des journalistes (Pierre Nadeau, Gérald Godin, Jacques LarueLanglois, Pierre Vallières, Charles Gagnon), des artistes (Pauline Julien), des leaders syndicaux (Michel Chartrand), des écrivains (Gaston Miron), des professeurs et des candidats aux prochaines élections municipales de Montréal.

17 octobre Le corps sans vie de Pierre Laporte est découvert dans le coffre d'une voiture.

18 octobre Le nombre de perquisitions effectuées par la police et l'armée s'élève à 642 , tandis que 343 personnes ont été arrêtées, sans que la police dévoile leurs noms. La Sûreté du Québec lance deux mandats d'arrestation contre Marc Carbonneau, 37 ans, chauffeur de taxi, et Paul Rose, 27 ans, professeur dans une institution secondaire de la Rive Sud. Ils sont accusés d'enlèvement et de meurtre. Le Gouvernement du Québec réitère l'offre de sauf-conduit aux seuls ravisseurs de Cross. 
19 octobre La police découvre la maison où Laporte a été détenu et assassiné. Les Communes d'Ottawa donnent leur assentiment à la proclamation des mesures de guerre par un vote de 190 contre 16.

20 octobre Les funérialles de Pierre Laporte ont lieu à Montréal sous une imposante surveillance policière et militaire.

21 octobre Le coroner du district de Montréal, Me Laurin Lapointe, rend publics les résultats de l'autopsie pratiquée sur le corps de Laporte. La mort de celui-ci aurait été provoquée par strangulation à l'aide d'une chaînette. Jean Marchand, ministre fédéral de l'Expansion économique régionale, déclare à Vancouver que le FRAP, parti d'opposition aux prochaines élections municipales de Montréal, fait partie du FLQ. Il rectifiera par la suite sa déclaration, invoquant sa connaissance imparfaite de la langue anglaise.

25 octobre Les élections municipales de Montréal ont lieu, sous la surveillance de l'armée. M. Drapeau est réélu maire de la ville avec $92 \%$ des voix. Les arrestations se font moins nombreuses mais les perquisitions continuent sans relâche. La Sûreté du Québec n'a pas encore reçu l'ordre de dévoiler les noms des personnes arrêtées, détenues et relâchées.

26 octobre Création d'un Comité d'aide aux personnes arrêtées en vertu de la Loi sur les mesures de guerre. Ses buts : assurer les contacts essentiels entre les détenus et leurs proches, voir aux besoins essentiels des familles concernées, porter à la connaissance du ministre de la Justice toute irrégularité constatée, etc. À Montréal, le procès de Claude Morancy, commencé le 9 septembre, est annulé en raison du climat existant et reporté à un autre terme des assises.

27 octobre M. Bourassa émet un communiqué dans lequel il annonce avoir été mis au courant de la possibilité d'un coup d'État au Québec. M. Drapeau déclare que «le terrorisme croissant au Québec a poussé certains citoyens de bonne foi à envisager la formation d'un gouvernement provisoire qui aurait été un ramassis de révolutionnaires ». Les membres du Comité d'aide aux personnes arrêtées commencent leurs visites dans les prisons. Certains détenus peuvent enfin rencontrer leur avocat et les proches parents sont admis dans les prisons. Dans une allocution prononcée devant le Club Richelieu à Ottawa, M. Réal Caouette suggère que Vallières, Gagnon et Chartrand soient envoyés au peloton d'exécution et passés par les armes l'un après l'autre, «de façon à permettre au suivant de dévoiler ses secrets:.

31 octobre La police fait savoir que 139 suspects se trouvent encore derrière les barreaux. 
2 novembre Le ministre fédéral de la Justice dépose un projet de loi sur les pouvoirs d'urgence provisoires, appelés à remplacer la Loi sur les mesures de guerre. Le juge Antonio Lamer rejette une demande d'habeas corpus présentée par Me Lemieux.

4 novembre Le Premier Ministre du Québec annonce que son gouvernement examine la possibilité de verser des compensations aux victimes innocentes arrêtées et détenues sans raison valable.

5 novembre 24 personnes détenues en vertu de la Loi sur les mesures de guerre comparaissent à Montréal devant le juge Ignace Deslauriers pour répondre de diverses accusations. Aucun cautionnement n'est accordé à Vallières, Gagnon, Larue-Langlois, Chartrand et Lemieux, qui récusent le tribunal et le régime. $\AA$ Ottawa, la Loi sur les pouvoirs provisoires d'urgence est adoptée en deuxième lecture.

6 novembre Dans la capitale fédérale, les députés créditistes réclament la peine de mort pour les crimes politiques.

7 novembre Bernard Lortie, 19 ans, arrêté la veille par la police, comparaît à l'enquête du coroner sur la mort de Laporte et avoue sa participaiton dans l'enlèvement du ministre; ses trois complices seraient les frères Paul et Jacques Rose ainsi que Francis Simard. À Québec, le ministre de la Justice déclare qu'il projette l'imposition de la carte d'identité obligatoire.

10 novembre Une motion d'amendement au code pénal visant à rétablir la peine de mort pour l'enlèvement et le meurtre politique est défaite aux Communes. Au cours des débats, le Premier Ministre du Canada estime que c'est l'inefficacité de la police qui a justifié la promulgation de la Loi sur les mesures de guerre. L'Association des policiers provinciaux du Québec se défend de cette accusation et fait savoir que s'il y a incompétence, «c'est celle de nos chefs ».

13 novembre Dans une lettre clandestine qu'il a réussi à faire sortir des locaux de police où il est détenu, Me Lemieux adresse au Barreau cinq demandes : l'accès à ses dossiers, l'obtention d'un cautionnement, le nolle prosequi dans les accusations portées contre lui, l'intervention vigoureuse du Barreau * face à la dégradation de la justice au Québec $\gg$ et la nomination d'un avocat ou d'un comité chargé de veiller au bon développement de son affaire.

16 novembre Devant l'Assemblée nationale du Québec, le député Jean Bienvenue suggère l'adoption d'un programme énergique et sévère en vue de mettre un terme au terrorisme. Ce programme prévoit notamment : le rétablissement de la peine de mort, un appui « la la ligne dure» en matière de libérations condition- 
nelles, une législation plus sévère et un contrôle plus énergique des drogues, une censure plus stricte du cinéma, des livres, des revues et des publications jaunes et révolutionnaires, une purge des ondes et de la presse écrite, l'épuration et la restauration de l'ordre et de l'autorité sur les campus des universités et des écoles secondaires, un recours au service militaire obligatoire si ces mesures ne donnent pas de résultats.

19 novembre $M$. Choquette révèle qu'il a entrepris des démarches visant la tenue d'une session spéciale des assises dès le mois de décembre, afin d'accélérer l'instruction des causes felquistes.

21 novembre De sa prison, Michel Chartrand intente une poursuite de $\$ 25000$ contre le ministre fédéral Jean Marchand, qui a tenu publiquement des propos évoquant la possibilité que le célèbre syndicaliste procède à l'enlèvement du président de la CSN, M. Marcel Pepin.

23 novembre Le gouvernement d'Ottawa s'apprête à réétudier la législation réagissant la vente des armes à feu.

25 novembre Lise Rose, sceur de Paul et de Jacques, refuse de témoigner au cours de l'enquête du coroner sur la mort de Laporte, alléguant avoir été déshabillée et maltraitée par les policiers; elle sera accusée d'outrage au tribunal et condamnée à 6 mois de prison.

26 novembre Menace de débrayage chez les policiers, à la suite des déclarations faites par leurs chefs, les politiciens et les journalistes concernant leurs actions face aux événements.

28 novembre Un sondage d'opinion révèle que $73 \%$ des Québécois approuvent la décision du gouvernement d'Ottawa de décréter la Loi sur les mesures de guerre, $48 \%$ des personnes interrogées se déclarent satisfaites du gouvernement fédéral de l'époque, alors que $52 \%$ le sont du gouvernement provincial.

1er décembre La Chambre des Communes adopte la Loi sur les pouvoirs d'urgence provisoires pour le maintien de l'ordre public par 174 voix contre 31 .

3 décembre La police découvre l'endroit où $M$. Cross est séquestré. Le diplomate britannique est libéré. En échange, ses ravisseurs (Jacques Lanctôt, Yves Langlois, Marc Carbonneau, Jacques et Louise CossetteTrudel) obtiennent un sauf-conduit et l'autorisation de partir pour Cuba dans un avion mis à leur dispo. sition par le gouvernement. Le ministre québécois de la Justice rend public le bilan des opérations policières entreprises depuis la promulgation de la Loi sur les mesures de guerre. D'après ce rapport, 
la police a procédé à 3068 perquisitions, au cours desquelles 4692 balles, 912 détonateurs, 677 bâtons de dynamite, 159 armes à feu, 22 armes blanches, 4 canettes de poudre à fusil, 3 grenades fumigènes et un chargeur ont été saisis. La police a également appréhendé 453 personnes, dont 403 ont été relâ. chées et 50 inculpées. Les juges ont refusé tout cautionnement à ces 50 personnes.

22 décembre Le Comité d'aide aux personnes arrêtées en vertu de la Loi sur les mesures de guerre publie un rapport préliminaire. Selon ce document, des abus auraient été commis à l'occasion des perquisitions (portes, fenêtres et murs défoncés à coups de hache; menaces et injures proférées devant de jeunes enfants; questions aux enfants, la nuit, alors que les parents avaient été amenés, armes au poing, par les policiers et les militaires; saisies inutiles) et des interrogations (gifles, coups, menaces, injures, femmes déshabillées, etc.). En général, les conditions de détention ont été raisonnablement correctes, si l'on exclut le caractère vétuste de certains centres et le fait que les personnes détenues ont été soumises à un régime alimentaire spécial. On dénonce cependant les conditions de détention à Parthenais et à Orsainville (cellules trop petites où l'on restait enfermé 24 heures par jour, fort éclairage jour et nuit, pas d'accès régulier aux douches, interdiction de fivres, papier, jeux, etc.).

28 décembre Les frères Rose, ainsi que Francis Simard, présumés coupables de l'assassinat de Laporte, sont arrêtés par la police. Dans une conférence de presse, le ministre de la Justice du Québec * restitue 》 aux juges leur pouvoir traditionnel d'accorder ou de refuser des cautionnements.

1971

4 janvier

7 janvier

8 janvier

21 janvier

L'enquête du coroner prend fin. Les frères Rose, Francis Simard et Bernard Lortie sont tenus criminellement responsable de la mort de M. Pierre Laporte.

Trois chefs d'accusation (meurtre, enlèvement et appartenance au FLQ) sont portés contre les quatre inculpés.

Michel Chartrand est condamné par le juge Roger Ouimet à un an de prison pour 4 outrages au tribunal.

95 plaintes sont présentées à l'Ombudsman pour dommages matériels occasionnés lors des perquisitions, conditions de détention incorrectes et dommages subis par les personnes arrêtées et relâchées sans accusation. 
23 janvier Incapable d'obtenir des subpoena pour les obliger à venir témoigner dans son procès, Paul Rose envoie des télégrammes à tous les directeurs de journaux, de postes de radio et de télévision. Il proteste contre la publicité faite autour de lui, qui constitue un procès avant le procès.

25 janvier Début du procès devant jury de Paul Rose, accusé du meurtre de Pierre Laporte. Le tribunal, présidé par le juge Marcel Nichois, siège, pour des raisons de sécurité, au quartier général de la Sûreté du Québec. L'accusé, qui n'a pas pu avoir l'assistance de Me Lemieux, incarcéré depuis le 16 octobre, décide d'assurer lui-même sa défense.

1er février Début, devant le juge Ouimet, du procès pour conspiration séditieuse contre Vallières, Gagnon, Chartrand, Lemieux et Larue-Langlois. Les accusés demandent, sans succès, la récusation du magistrat.

11 février L'acte d'accusation contre «les cinq 》 est cassé.

12 février Chartrand et Lemieux sont libérés sous caution. Les autres inculpés seront gardés en prison sous prétexte de la nécessité de protéger le public. Selon Me Nicole Dreyfus, observateur de l'Association internationale des juristes démocrates, le procès des cinq est nettement politique, en raison de la nature de l'accusation portée et du contexte dans lequel elle l'a été.

15 février Me Lemieux se dit prêt à défendre Paul Rose, mais celui-ci refuse ses services. Paul Rose est expulsé et réadmis à la cour à plusieurs reprises. Le juge nomme un observateur (amicus curiae) dont la mission est d'indiquer au tribunal certains points de droit et de fait. On apprend que les six procureurs ad hoc engagés le 30 octobre pour s'occuper des procès felquistes sont payés $\$ 300$ par jour.

24 février Me Roger Lailemand, du Barreau de Bruxelles, observateur de la Fédération internationale des ligues des droits de l'homme, arrive à Montréal pour assister au procès de Paul Rose.

1er mars Sept jeunes femmes appartenant au Front de libération de la femme, prennent d'assaut la tribune des jurés devant juger Paul Rose. Elles seront immédiatement condamnées à un mois de prison chacune pour outrage au tribunal et incarcérées.

3 mars Une manifestation pour libérer Vallières et Gagnon a lieu.

10 mars Dix accusations pour incitations au meurtre et à l'enlèvement de diverses personnalités du monde politique et judiciaire sont portées contre Vallières. Une nouvelle accusation de conspiration séditieuse est portée contre Vallières, Gagnon et Larue-Langlois. 
Le Procureur général du Québec annonce qu'il arrête les procédures dans les cinq causes contre Vallières et Gagnon remontant à 1966 et n'ayant pas encore fait l'objet d'un procès.

12 mars

13 mars

Québec manifeste son intention d'indemniser les victimes innocentes de la crise d'octobre.

Le jury prononce un verdict de culpabilité contre Paul Rose, qui est condamné sur-le-champ à l'emprisonnement à vie (Me Lemieux fera appel de cette décision de culpabilité le $\mathbf{3 0}$ mars; l'appel sera examiné le 18 avril 1975, mais Paul Rose décidera de le retirer le 24 de ce mois).

22 mars Une nouvelle demande de mise en liberté sous caution par Vallières et Gagnon est rejetée par le tribunal. Au cours de ce mois de mars, sera mis sur place à Québec, dans le plus grand secret, le Centre d'analyse et de documentation (CAD), chargé de renseigner le gouvernement sur les questions de « sécurité nationale » et de subversion. Il compilera plus de 30000 fiches personnelles sur autant de citoyens, 6000 dossiers sur autant de groupes et 1800 dossiers dits d'événements. Cet organisme sera démantelé le 31 mars 1977 et les 30000 fiches personnelles seront détruites; les autres dossiers seront remis à la direction générale de la sécurité publique.

26 avril Début du nouveau procès pour conspiration séditieuse contre Vallières, Gagnon et Larue-Langlois devant le juge Laurent Bélanger; le procès sera renvoyé aux prochaines assises.

30 avril Le gouvernement fédéral annonce qu'il ne fera pas reconduire la Loi sur les mesures de guerre. Un comité spécial étudie un projet de loi permanente sur l'ordre public.

10 mai Début du procès de Francis Simard pour le meurtre de Pierre Laporte. Après avoir été condamné quatre fois pour outrage au tribunal, l'inculpé, qui se défend seul, décidera de garder le silence jusqu'à la fin. Il sera déclaré coupable le 19 et condamné à la prison à vie. Son appel sera rejeté le 30 août 1973.

12 mai Début du nouveau procès devant jury contre Gagnon et Larue-Langlois, qui seront acquittés le 15 juin. Gagnon sera libéré sous caution, tandis que Larue-Langlois restera en détention. Tous deux devront de nouveau être jugés sous d'autres chefs d'accusation.

ler juin Le réseau anglais de Radio-Canada annonce la diffusion d'une émission spéciale sur les procès politiques au Québec. À la suite d'une injonction éma- 
nant des tribunaux, l'émission sera retirée du progranme.

24 juin Vallières est libéré sous caution, après quatre ans et demi de détention.

16 août Le ministre de la Justice du Québec décide d'arrêter les procédures criminelles contre 35 personnes accusées en vertu de la Loi sur les mesures de guerre.

3 septembre Ces 35 personnes exigeront, dans une lettre adressée au ministre, d'être acquittées.

août Le gouvernement fédéral publie un livre blanc sur La Défense dans les années 70, selon lequel les forces armées seront réorientées pour assurer la sécurité interne et la défense de l'intégrité du territoire canadien face à la menace de l'indépendance du Québec. Il prévoit également la création d'un groupe de planification et de recherche en matière de sécurité, afin de voir venir les événements. La GRC met en place la section $G$ (anti-terroriste) de ses services de sécurité, dont les opérations se dérouleront exclusivement au Québec.

12 septembre Paul Rose est transféré de Sainte-Anne-des-Plaines à Saint-Vincent-de-Paul; la raison invoquée est l'évasion d'un groupe de détenus dont faisait partie un terroriste.

13 septembre Début du procès de Bernard Lortie pour l'enlèvement de Pierre Laporte. L'accusé, qui se défend seul, sera expulsé à plusieurs reprises de la cour. Le 22 novembre, il sera reconnu coupable et condamné à 20 ans d'emprisonnement.

23 septembre Le mouvement de défense des prisonniers politiques » du Québec dénonce les conditions de détention de Paul Rose à l'Unité spéciale de détention de Saint-Vincent-de-Paul (cellule de 4 pieds sur 8 , éclairage et surveillance 24 heures par jour, etc.).

18 octobre Début du procès de Paul Rose pour l'enlèvement de Laporte devant le juge Fernand Legault. L'accusé se défend seul et sera expulsé plusieurs fois de la salle d'audience. Le 26 novembre, il sera déclaré coupable et condamné à l'emprisonnement à vie. Il fera appel de sa condamnation le 10 décembre, mais sa demande sera rejetée le 18 avril 1975.

19 décembre La GRC émet un faux communiqué du FLQ, dans lequel on dénonce l'abandon de l'action terroriste par Vallières et son ralliement au $P Q$, identifié comme un parti «petit bourgeois »; le communiqué est rédigé sur un « ton maoïste» afin de créer de la confusion parmi les felquistes et incite les Québécois à la violence. 
1972

7 février Début du procès de Jacques Rose pour enlèvement devant le juge Eugène marquis. L'accusé, habillé en pyjama et en robe de chambre, doit être traîné de force devant la cour, où il sera défendu par Me Lemieux. Le procès se terminera le 15 mai par le désaccord des jurés.

18-19 avril L'armée canadienne procède à l'opération \& Neet Fitch »: 46 généraux et colonels se réunissent à Montréal pour étudier un plan d'occupation éventuelle du Québec en cas d'insurrection apprébendée ».

mai Les trois chefs des principaux syndicats sont arrêtés et condamnés à la suite d'une grève illégale du Front commun syndical.

8 juillet La Loi 51 modifiant certaines dispositions de la Loi de police entre en vigueur au Québec. Elle accorde des pouvoirs très étendus aux policiers « dans la lutte contre le crime organisé et la subversion ».

15 octobre Le deuxième procès contre Jacques Rose pour l'enlèvement de Pierre Laporte s'ouvre à Montréal. Le jury, présidé par le juge Charles-Noël Barbès, acquittera l'inculpé le 9 décembre. Le rapport Dare dans «le renforcement des dispositifs d'intervention fédérale en temps de crise » est remis au gouvernement d'Ottawa. Ce document, qui sera présenté au Parlement canadien en mars 1974, prévoit la mise sur pied d'un centre de planification des mesures d'urgence, chargé notamment du maintien de l'ordre en temps de crise.

1973

16 janvier Début à Montréal, devant le juge Bisson, du nouveau procès pour meurtre contre Jacques Rose, qui sera acquitté le 22 février et libéré sous caution.

13 février La Cour d'appel du Québec refuse à Paul Rose un deuxième procès pour meurtre, en décidant qu'un accusé aux assises ne peut pas récuser péremptoirement un candidat-juré après l'avoir récusé pour cause. Au printemps, la Sûreté du Québec lance l'opération «Québec 95 », vaste enquête sur ce que la police appelle \& les mouvements d'influence nationale a au Québec. Le gouvernement fédéral dépose en Chambre un projet de loi visant à légaliser, sous certaines conditions, l'écoute électronique (cette loi entrera en vigueur le ler juillet 1974).

juillet Le troisième procès contre Jacques Rose pour complicité après le fait dans l'enlèvement de Pierre La- 
porte se termine par la condamnation de l'inculpé à 8 ans de prison; sa sentence sera maintenue en appel (juin 1974).

1974

janvier
Le Procureur général du Québec décide de retirer les dernières accusations qui pesaient encore contre Lortie et Simard.

1975

Ottawa annonce qu'aucune amnistie ne sera accordée aux ravisseurs de Cross, dont certains ont manifesté leur intention de rentrer au pays.

1976

8 janvier
Création d'un comité d'information sur les prisonniers politiques au Québec. Celui-ci dénoncera la séparation des frères Rose, le fait que les «détenus politiques » demeurent 23 heures par jour en cellule et la politique de la Commission nationale des libérations conditionnelles, qui retarde l'élargissement des felquistes à cause de la proximité des Jeux olympiques de Montréal.

A l'occasion des Jeux olympiques, 16000 militaires sont mobilisés au Québec.
1977

18 mai

15 juin

6 juillet
Le ministre de la Justice du Québec, Me Marc-André Bédard, confie à Me Jean-François Duchaîne le mandat de mener une enquête afin « de recueillir des données de toutes personnes, groupes, organismes, policiers ou autres intéressés par la crise d'octobre $1970 \gg$.

Le gouvernement québécois annonce la création d'une commission d'enquête sur le cambriolage de l'Agence presse libre du Québec; ce sera la Commission Keable, dont le mandat sera par la suite élargi pour enquêter sur les opérations policières en territoire québécois » et dont les audiences débuteront en octobre. Les travaux de cette commission seront paralysés à diverses reprises pendant l'année 1979, à la suite de requêtes présentées par le gouvernement fédéral et par le service de police de la CUM. L'affaire sera portée jusqu'à la Cour suprême du Canada, qui rendra un jugement restreignant l'enquête aux seuls corps policiers du Québec et à l'étude de certains documents spécifiques de la GRC.

Le Gouvernement fédéral annonce la création de la Commission McDonald, chargée d'enquêter sur les activités illégales de la GRC ainsi que sur la «sécurité nationale » au Canada. 
décembre Le ministre de la Justice du Québec fait part de son intention de créer, en 1978, un groupe d'analyse sur la sécurité de l'État québécois ».

1978

janvier

18 juillet

7 décembre

13 décembre Jacques et Louise Cossette-Trudel rentrent au Québec après un long exil à Cuba et en France. Ils comparaîtront le lendemain devant le juge en chef de la Cour des sessions de la paix de Montréal. Libérés sous caution le 18, ils enregistreront, le 31 mai 1979, un plaidoyer de culpabilité aux accusations d'enlèvement et de séquestration de $M$. Cross et seront condamnés à 2 ans moins un jour de prison et à 3 ans de probation.

1979

7 janvier Jacques Lanctôt rentre également au Québec. Il choisit un procès devant un juge seul le 24 septembre et plaide coupable, le 7 novembre, devant le juge en chef de la Cour des sessions de la paix de Montréal, qui le condamne à 3 ans de prison et à 3 ans de probation. On accorde à Francis Simard un régime d'absences temporaires sans escorte.

février Jacques Rose, qui avait refusé une libération conditionnelle de jour en juillet 1978, obtient une libération conditionnelle complète.

novembre À loccasion des audiences publiques de la Commission Keable, on apprend que la police avait infiltré le FLQ pendant la crise d'octobre, négligé d'arrêter des individus et fabriqué des faux communiqués.

1980

avril

Les Époux Cossette-Trudel obtiennent leur libération conditionnelle.

Voici donc, sommairement décrits, les principaux événements auxquels eurent à faire face, non seulement l'ensemble de la population du Québec, mais aussi et en particulier les autorités policières, judiciaires et pénitentiaires de la province. Examinons maintenant la manière selon laquelle les divers secteurs de l'admi- 
nistration de la justice pénale abordèrent ces problèmes et les dilemmes qu'ils eurent à résoudre.

\section{RÉPERCUSSIONS SUR L'ADMINISTRATION DE LA JUSTICE PÉNALE}

Les événements d'octobre 1970 ont eu des répercussions considérables sur les institutions canadiennes et québécoises de justice pénale. La législation, la police, la poursuite, les tribunaux et l'appareil correctionnel ont été, en effet, soumis à de rudes épreuves et ont fait l'objet de nombreuses critiques.

\section{A. La législation}

Sur le plan législatif, les événements d'octobre ont été à l'origine de la renise en vigueur de certaines lois ainsi que de la promulgation de nouveaux textes. Par ailleurs, bien que l'établissement d'un lien de causalité directe soit fort difficile en cette matière, il n'est pas sans intérêt de souligner que, depuis 1970 , le Canada et le Québec se sont donné des lois touchant d'assez près le problème du terrorisme et de la subversion. Tel est le cas, par exemple, au niveau fédéral, des amendements au code criminel en vue de légaliser l'écoute électronique (1974), de punir plus sévèrement la possession et la vente illégales des armes à feu (1976) ou de considérer les membres de l'armée comme des agents de la paix (art. 2). Au niveau provincial, l'exemple le plus frappant est sans aucun doute la Loi 51 modifiant la Loi de police de 1968, qui fut sanctionnée le 8 juillet 1972 ; cette loi accroît considérablement les pouvoirs de la Commisșion de police du Québec, notamment en ce qui concerne les perquisitions, les saisies, le témoignage confidentiel de certaines personnes et les enquêtes «sur les activités d'une organisation ou d'un réseau, ses ramifications ou les personnes qui y concourent », lorsqu'il y a des « raisons de croire que, dans la lutte contre le crime organisé ou le terrorisme et la subversion ${ }^{3}$, il est de l'intérêt public d'ordonner la tenue d'une telle enquête ».

Néanmoins, ce sont surtout deux lois fédérales qui ont fait couler le plus d'encre et soulevé le plus de critiques. Il s'agit de

3. C'est nous qui soulignons. Marc Laurendeau fait remarquer l'habileté d'inscrire, dans un même texte légal, deux idées qui semblent bien s'accoler : le crime organisé d'une part, et le terrorisme et la subversion d'autre part ; d'après lui, on réussit, par cette ruse, à mêler deux réalités dans l'esprit du public et des organismes de répression (op. cit., note 1, p. 15). 
1a Loi sur les mesures de guerre et le Règlement de 1970 concernant l'ordre public, ainsi que de la Loi sur les pouvoirs d'urgence provisoires pour le maintien de l'ordre public au Canada.

La loi sur les mesures de guerre fut promulguée en 1914, au début de la Première Guerre mondiale. Elle accordait au gouvernement central des pouvoirs illimités, lui permettant d'édicter les ordonnances et les règlements qu'il jugerait nécessaires ou utiles en raison de l'existence d'une guerre, d'une invasion ou d'une insurrection, réelles ou appréhendées, et elle entrait en vigueur sur simple déclaration, par le Gouverneur en conseil, de l'existence d'un de ces trois événements. Depuis 1914, cette loi n'a été proclamée qu'en deux occasions : le $1^{\text {er }}$ septembre 1939 (début de la Deuxième Guerre mondiale) et le 16 octobre 1970. Ce jour-là, le Gouverneur général du Canada proclamait «qu'un état d'insurrection appréhendée existe et a existé depuis le 15 octobre $1970 \gg$, étant donné :

qu'il existe actuellement dans la société canadienne un noyau ou groupe appelé le Front de libération du Québec qui préconise l'emploi de la force ou la perpétration de crimes, y compris le meurtre, les menaces de mort et l'enlèvement, et y a recours, comme moyen ou instrument aux fins de réaliser un changement de gouvernement au Canada.

C'est en vertu de cette loi que le « règlement de 1970 concernant l'ordre public » fut proclamé le 16 octobre. Ce règlement déclarait «association illégale 》 le FLQ ainsi que tout autre groupement qui lui succéderait ou qui préconiserait l'emploi de la force ou la perpétration de crimes comme moyen de réaliser un changement de gouvernement au Canada. Toute personne membre d'une telle association, qui communiquerait ses déclarations, préconiserait ou favoriserait ses « actes, desseins, principes ou lignes de conduite» ou lui fournirait de l'aide ou de la coopération, pouvait être déclarée coupable d'un acte criminel et encourir une peine d'emprisonnement d'au plus cinq ans. Dans l'application de ce règlement, d'autres droits fondamentaux des citoyens étaient suspendus ou atténués. Tout agent de la paix, ce qui comprenait les membres des forces armées canadiennes, pouvait procéder, sur la base de «soupçons raisonnables 》, à des arrestations, perquisitions et saisies sans mandat. La personne arrêtée devait, en attendant son procès, demeurer en prison, ne 
pouvant être relâchée sous caution sans le consentement du procureur général de la province. Le délai de comparution devant un juge de paix était fixé à 7 jours, le procureur général pouvant le porter à 21 jours. Le fardeau de la preuve était renversé, en outre, l'article 8 stipulant, en effet, que le fait d'avoir assisté à une réunion de l'association illégale, parlé publiquement en sa faveur ou transmis ses déclarations constituait, à défaut de preuve du contraire, la preuve que cette personne était membre de l'association illégale ».

Quant à la Loi sur les pouvoirs d'urgence provisoires pour le maintien de l'ordre public au Canada (novembre 1970), destinée à remplacer la législation précédente et à demeurer en vigueur jusqu'au 31 avril 1971, elle conservait certains pouvoirs spéciaux déjà définis dans le règlement du 16 octobre, en particulier celui de perquisitionner et d'arrêter sans mandat, ainsi que celui de détenir une personne sans qu'une accusation soit portée tout de suite contre elle. Elle prévoyait également le même type de pénalités pour les mêmes catégories de personnes et consacrait le renversement du fardeau de la preuve. Par contre, elle réduisait les délais de comparution de la personne arrêtée à 3 jours et à 7 si le procureur général en donnait l'ordre. Elle maintenait finalement la plupart des droits définis dans la Déclaration canadienne des droits de 1960, notamment l'interdiction faite aux autorités policières d'imposer des traitements cruels et inusités aux détenus, le droit d'une personne arrêtée d'être promptement informée des motifs de son arrestation ou de sa détention et de retenir les services d'un avocat, le droit d'une personne accusée à la présomption d'innocence et à une audition impartiale de sa cause, etc.

Ces législations ont fait l'objet de nombreuses contestations judiciaires de la part des accusés d'octobre et de multiples critiques provenant de certaines personnalités et organisations. La plupart de ces critiques apparaissent avec une grande clarté dans la requête en habeas corpus présentée, le 14 janvier 1971, par MM. Chartrand, Vallières, Gagnon et Lemieux devant le juge Bergeron de la Cour du Banc de la Reine de Montréal. Outre le fait que ces lois - à l'exception peut-être de la dernière - avaient mis en veilleuse les droits fondamentaux garantis aux citoyens par la Déclaration canadienne de 1960, on leur reprochait, tout d'abord, de ne pas avoir été rigoureusement 
justifiées. Mises à part les lettres du directeur de la police de Montréal (adressées le 15 octobre à MM. Drapeau et Saulnier) et celles des autorités municipales et du Premier Ministre du Québec (adressées au Premier Ministre du Canada les 15 et 16 octobre respectivement), aucune preuve n'a jamais été fournie, ni au Parlement canadien ni ailleurs, d'un état d'insurrection appréhendée au Québec. Dans ces conditions, quelles preuves trouverait-on dans ces lettres? Celle du directeur de la police de Montréal, M. Marcel Saint-Aubin, dont les arguments ont été par la suite repris par MM. Bourassa, Drapeau et Saulnier, parlait de l'existence "d'un mouvement subversif extrêmement dangereux », qui s'était développé depuis quelques années "en vue de préparer le renversement de l'État légitime au moyen de sédition et d'une insurrection armée éventuelle», ainsi que des difficultés concernant les enquêtes menées par les policiers à la suite des enlèvements de $\mathrm{MM}$. Cross et Laporte et les moyens mis à leur disposition. Quant aux lettres de MM. Bourassa, Drapeau et Saulnier, les demandes d'intervention formulées étaient davantage basées sur de simples impressions ou convictions personnelles que sur une analyse rationnelle de la situation.

La proclamation de la Loi sur les mesures de guerre et du règlement de 1970 était-elle nécessaire et utile dans les circonstances? N'était-elle pas plutôt un geste par lequel le gouvernement voulait rassurer la population en montrant qu'il faisait «quelque chose »? Si le Procureur général du Québec avait des « motifs raisonnables» de croire que certaines personnes étaient déterminées à renverser le gouvernement par la violence ou par d'autres moyens illégaux, il avait déjà, selon l'expression même du code pénal, « des motifs raisonnables et suffisants 》 de les appréhender sous l'empire des lois « ordinaires» en vigueur. A la limite, comme soulignait la Ligue des droits de l'homme, rien n'empêchait le gouvernement fédéral de présenter des amendements au code pénal et de se faire accorder par le Parlement tous les pouvoirs extraordinaires dont il aurait eu besoin pour assurer la sécurité des citoyens, démanteler les mouvements séditieux et maintenir l'ordre dans le pays *.

4. Un sondage d'opinion effectue en mars 1971 montrait que les citoyens du Québec se sont sentis davantage menacés par l'armée ou par la police que par le FLQ (M. Bellavance et M. Gilbert, L'Opinion publique et la crise d'octobre, Montréal, Les Editions du Jour, 1971). 
D'autres hypothèses, plus plausibles, ont été avancées au sujet de ces lois spéciales : donner un caractère de légitimité aux détentions illégales déjà effectuées ${ }^{5}$, avoir cédé à la panique, couper le courant de sympathie manifesté par certains groupes ou personnes envers le FLQ, créer un choc psychologique permettant au gouvernement de reprendre l'initiative, une provocation planifiée visant à roder l'appareil répressif à l'échelle du pays, à centraliser toutes les données disponibles sur la subversion (et, plus particulièrement, celles concernant la subversion séparatiste) et à renforcer l'unité canadienne par la désorganisation et la dislocation aussi complète que possible des organismes qui encadraient le nationalisme québécois ${ }^{6}$.

Quoi qu'il en soit, et même si, d'une façon générale, la population a appuyé l'intervention énergique du gouvernement durant la crise d'octobre, on ne peut s'empêcher de penser que ces lois spéciales ont été des moyens disproportionnés aux besoins du moment.

Dans la requête en habeas corpus déjà mentionnée, les quatre détenus contestaient également la constitutionnalité de la loi de novembre 1970 concernant l'ordre public (leurs remarques s'appliquant aussi au règlement du 16 octobre). Ils soulignaient, en premier lieu, qu'il n'était pas de la compétence du Gouvernement du Canada, c'est-à-dire du pouvoir exécutif, de porter un jugement sur le caractère de légalité ou d'illégalité d'une association, même si les activités de celle-ci sont contraires aux lois du pays; tel qu'il appert d'une abondante jurisprudence, la prérogative de porter un jugement de nature juridique appartient exclusivement aux tribunaux, en vertu du principe de la séparation des pouvoirs, reconnu comme inviolable par la tradition britannique.

Par ailleurs, l'article 8 de la « loi Turner » était inconstitutionnel du fait qu'il permettait la mise en preuve d'actes antérieurs à sa promulgation et qu'il renversait le fardeau de la preuve, le faisant porter sur l'accusé et non sur la poursuite. Ceci est non seulement contraire à la doctrine et à la jurisprudence, mais vient en contradiction avec l'article 2 (f) de la Déclaration canadienne

5. R. Haggart et A.E. Golden, Octobre 70, un an... après, Montréal, Hurtubise-HMH, 1971, p. 65.

6. Pierre Vallières, L'Exécution de Pierre Laporte, Montréal, Editions Québec-Amérique, 1977, p. 25-26. 
des droits, selon lequel «nulle loi du Canada ne doit s'interpréter ni s'appliquer comme privant une personne accusée d'un acte criminel du droit à la présomption d'innocence jusqu'à ce que la preuve de sa culpabilité ait été établie en conformité avec la loi, après une audition impartiale et publique de sa cause par un tribunal indépendant et non préjugé ». Ce qui est surprenant, c'est que la «loi Turner» reconnaissait explicitement que cette disposition de la Déclaration canadienne des droits s'appliquait toujours. Par surcroit, l'un des aspects les plus dangereux de cet article 8 était son caractère rétroactif. Malgré les affirmations opposées du législateur et les déclarations du Barreau du Québec, plusieurs juristes ont reconnu et dénoncé l'aspect rétroactif de ce texte, comme contraire aux principes fondamentaux du droit pénal. Telle a été également l'interprétation donnée par les juges Ouimet et Chevalier lors des procès de Côme Leblanc et de Raymond Cormier, accusés d'appartenance au FLQ et jugés en janvier 1971.

On a finalement critiqué le fait que la loi de 1970 pouvait entraîner l'incarcération non seulement de celui dont l'appartenance au FLQ aurait été démontrée, mais aussi du citoyen soupçonné de faire partie de cette association ou de tout groupe lui succédant. Une personne pouvait, en vertu de ces législations, passer une période de temps passablement longue en prison sans même qu'une accusation fût portée contre elle et cela, pour la seule raison qu'un policier aurait pu la soupçonner d'avoir des relations discutables.

En somme, cette analyse permet non seulement de souligner les dangers qui peuvent découler de la promulgation et de la mise en application de lois d'exception, mais également de faire ressortir comment les principes sous-jacents aux libertés civiques peuvent être violés par le législateur lui-même qui n'a pas cru opportun d'envisàger d'autres moyens susceptibles de faire face à une situation difficile, mais dont la portée a été, pour des raisons obscures, nettement exagérée.

\section{B. La police}

Les lois spéciales de 1970 accordaient - nous venons de le voir - des pouvoirs considérables à la police. Dans ces conditions, il n'est pas étonnant que les forces policières aient été 
l'objet de sévères critiques à l'occasion de l'exercice de leur pouvoir discrétionnaire. C'est ainsi que le Protecteur du citoyen, dans une lettre adressée au ministre de la Justice du Québec en mars 1971, se disait incapable d'admettre que la première liste de suspects ait été préparée à partir de critères aussi imprécis ; que les directives précédant l'opération d'octobre aient été aussi laconiques et appliquées de façon différente d'un endroit à l'autre; qu'on ait pu procéder aux visites des licux et aux perquisitions avec aussi peu de modération et de souci de la propriété; que les interrogatoires aient été conduits aussi lentement et sans plus de planification, forçant des personnes arrêtées pour simples fins d'identification à attendre plusieurs jours avant de pouvoir se justifier; que la coordination entre les forces policières n'ait pas été mieux assuiée; qu'on ait pu saisir autant d'objets et de documents inutiles, dont la quasi-totalité, plus de deux mois après, était encore retenue. Ajoutons à ces remarques de l'Ombudsman le refus - au moins pendant les premières semaines - de permettre tout contact entre la personne arrêtée et son avocat et l'imposition, par la suite, d'une présence policière au cours des conversations entre avocat et prévenu; la saisie des dossiers de certains défenseurs (Me Lemieux), en flagrante violation du principe du secret professionnel; des cas de brutalité et d'humiliation. Entre octobre et décembre 1970, la police procéda à plus de 3000 perquisitions et arrêta 450 citoyens québécois, qui restèrent en moyenne une semaine derrière les barreaux, la grande majorité étant par la suite relâchée sans qu'aucune accusation ne soit portée contre eux et n'ayant subi, au cours de cet emprisonnement, qu'un interrogatoire superficiel et souvent futile.

L'intervention des forces policières pendant la crise d'octobre peut être critiquée à un autre niveau, soit celui de leur contribution à la proclamation des lois spéciales qu'elles eurent par la suite à appliquer. Il convient à cet égard de rappeler que ce fut surtout la lettre adressée le 15 octobre par le directeur de la police de Montréal aux autorités municipales qui a été à l'origine de ces législations. On y faisait allusion à «l'ensemble des activités des réseaux de ce mouvement séditieux 》 (FLQ), à 《la somme incroyable de vérifications et de recherches $\gg$ imposées à la police, au "volume et à la complexité des preuves à recueillir et à conserver» ainsi qu'à «la lenteur des procédures et les 
contraintes qui résultent des mécanismes et des moyens légaux dont nous disposons actuellement ».

La dernande de pouvoirs spéciaux était-elle justifiée ? Nous ne le croyons pas. Certes, une appréciation effectuée dix ans après ne tient pas nécessairement compte de l'atmosphère particulière qui entoura la crise d'octobre. Quoi qu'il en soit, et pour mieux situer le problème, il convient de souligner un certain nombre de faits que les recherches et les enquêtes ultérieures, notamment celles menées par la Commission Keable, ont dévoilés : 1) La presque totalité des nembres du FLQ 1970 figurait déjà, de façon assez notoire, dans les dossiers de recherche de la police, la GRC ayant même réussi à s'installer dans le logement situé au-dessus de l'endroit où $M$. Cross était détenu; par conséquent, la crise d'octobre avait un certain caractère de prévisibilité ${ }^{7}$. 2) La police connaissait dès le début le nom de tous les ravisscurs de Laporte, certains d'entre eux ayant même fait l'objet de filatures. 3) La police connut assez tôt la participation d'un sixième homme à l'enlèvement de Cross; cependant, celui-ci ne fut jamais inquiété avant les révélations faites en 1978 dans le cadre des audiences de la Commission Keable. 4) La section anti-terroriste de la police de Montréal ne transmit jamais tous ses renseignements aux autorités compétentes. 5) La police avait réussi à infiltrer les cellules felquistes dès le début de la crise.

Par ailleurs, une analyse plus fouillée des faits aurait sans doute contribué à dédramatiser la situation et à nuancer les demandes policières. C'est ainsi, par exemple, qu'une bonne proportion des armes à feu trouvées dans certaines automobiles lors des fouilles appartenaient à des chasseurs (l'automne est la période de chasse au Québec) et que les vols de bâtons de dynamite pouvaient être dus à toutes sortes de raisons (les cultivateurs et les bûcherons utilisent de la dynamite, parfois obtenue illégalement, pou: déraciner les souches ou faire sauter les digues de castors), cet explosif se détériorant d'ailleurs assez rapidement s'il n'est pas entreposé dans un endroit frais, sec et aéré.

Dans ces conditions, pourquoi avoir insisté sur l'extrême urgence «d'obtenir des résultats concrets »? Certes, comme nous venons de le suggérer, en raison d'une analyse déîciente et

7. Marc Laurendeau, op. cit., note 1, p. 147. 
incomplète des événements et de l'absence d'un centre de traitement de l'information reçue, mais aussi à cause du manque de coordination - au moins au début -, du caractère inhabituel d'un travail conjoint, de l'effet de surprise, du fait que le FLQ avait engagé le débat sur la place publique et non pas au niveau auquel les policiers sont accoutumés et de la tendance à évaluer les forces felquistes par rapport à la somme d'énergie déployée dans la recherche des ravisseurs (ce qui eut comme effet de multiplier le nombre des présumés sympathisants du FLQ).

Ainsi, les corps policiers montrèrent-ils, au cours de la crise, un grand sens de l'organisation (les trois services de police - GRC, Sûreté du Québec et police de Montréal - se sont trouvés réunis sous une direction unique), mais également un manque assez général de flair et d'imagination ${ }^{8}$. Lorsque la police s'est plainte que les mécanismes ordinaires de la loi ne lui permettaient pas de combattre le terrorisme, elle se discréditait elle-même et niait l'aisance avec laquelle elle avait élucidé la plupart des infractions commises au nom du FLQ depuis 1963, dont le taux de réussite était infiniment plus élevé que celui enregistré pour les délits de droit commun. Il est surprenant de consíater que la découverte des coupables des événements d'octobre ne fut pas effectuée grâce aux pleins pouvoirs accordés par les lois d'exception, mais par le travail patient et compétent, bien qu'ordinaire, des policiers.

\section{La poursuite}

«Les procès des accusés d'octobre ont dégénéré en batailles rangées », pouvait-on lire, en guise de titre, dans une chronique judiciaire parue dans un important journal quotidien de Montréal ${ }^{9}$.

Choisis personnellement par M. Choquette, procureur général du Québec, et payés $\$ 300$ par jour, les procureurs \& spéciaux » de la Couronne ont eu à affronter des situations inédites. Obligés de prouver des accusations aussi « fuyantes » que celles de libelle séditieux, d'encouragement ou d'appartenance à une association illégale, de conspiration séditieuse, etc., les représentants du ministère public ont souvent eu recours, faute d'argu-

8. Marc Laurendeau, op. cit., note 1, p. 181.

9. Le Devoir, 1er mars 1971. 
ments plus solides, à l'allusion ou à la suggestion. Ce recours à des «preuves» suggestives ou allusives s'est surtout manifesté lors du procès du jeune Côme Leblanc devant le juge Ouimet. Outre le fait que l'inculpé et ses camarades avaient distribué des copies du manifeste felquiste, les procureurs firent référence à des livres trouvés dans la valise d'un de ses amis, à une carabine tronçonnée, au fait que l'accusé vivait de l'assurance-chômage, aux cours qu'il avait suivis, aux affiches collées sur le mur de son salon, etc. Par ailleurs, la Couronne l'interrogea longuement sur ses opinions politiques ainsi que sur la nature de ses lectures et de ses discussions.

De la même façon, le procureur dans le procès intenté à Pierre Vallières, en avril 1971, pour conspiration séditieuse, avait déclaré, lors d'une conférence de presse, que l'accusé serait jugé «par ses idées, ses écrits, ses intentions et ses paroles».

Ces interventions firent l'objet de sévères critiques de la part de certains magistrats, avec toutefois des conséquences fort diverses. C'est ainsi, par exemple, que le procureur ayant fait les déclarations ci-dessus rapportées dans la cause contre Vallières fut réprimandé par le juge qui présidait l'affaire, sans que cependant le procès soit annulé, comme le demandait l'accusé, en raison du grave préjudice que cette déclaration pouvait lui causer et sans que son auteur soit lui-même accusé d'outrage au tribunal. Parallèlement, la décision du juge Ouimet de casser l'acte d'accusation de conspiration séditieuse contre Vallières, Gagnon, Chartrand, Lemieux et Larue-Langlois, entachée d'un vice de forme tellement fondamental (absence de «détails suffisants pour renseigner raisonnablement les prévenus sur les actes ou omissions à prouver contre eux »), que non seulement le fait de laisser l'accusation se poursuivre en vertu de cet acte «représenterait une injustice envers les accusés», mais qu'il «était impossible au tribunal, même en faisant des efforts fébriles d'imagination, de tenter de le réparer en ordonnant que l'on fournisse des particularités 》, constituait, selon un journaliste ${ }^{10}$, « une gifle monumentale à l'endroit des procureurs spéciaux à honoraires très élevés et aussi du ministre de la Justice du Québec dont la signature apparaît au bas de l'acte d'accusation ».

10. Claude Ryan, Le Devoir et la crise d'octobre, Montréal, Leméac, 1971, p. 238. 
Lors des procès contre les accusés de la crise d'octobre, la poursuite mérite également d'être critiquée par le recours qu'elle fit au preferred indictment, procédure qui permet d'envoyer les prévenus à leur procès directement, c'est-à-dire sans enquête préliminaire.

Finalement, le ministère de la Justice décidait, en août 1971, d'arrêter les procédures engagées contre 35 personnes détenues en vertu de la Loi sur les mesures de guerre. D'abord interprété comme un acte de clémence de la part du gouvernement, ce recours au nolle prosequi donna lieu presque immédiatement à un tollé de protestations. En effet, le nolle prosequi ne signifiait nullement que le ministère retirait les accusations qui pesaient contre ces personnes, mais uniquement qu'il avait décidé de suspendre ces accusations, avec possibilité théorique de remettre leur procès à plus tard. Cela signifiait encore que chacune de ces 35 personnes pouvait être amenée devant les tribunaux au cours de la semaine, du mois ou des années suivantes si le Procureur général en décidait ainsi et que, par ailleurs, ces personnes n'étaient pas lavées de tout soupçon dans l'esprit du public. Cette situation fut jugée inacceptable, en raison de certaines conséquences qu'elle pouvait engendrer, la plus importante étant sans doute l'impossibilité dans laquelle se trouvaient ces individus de faire établir leur totale innocence (ce qui était contraire à la Déclaration canadienne des droits et aux principes fondamentaux du droit pénal) ainsi que de se qualifier pour bénéficier de l'indemnisation aux victimes arrêtées sans raison et relâchées par la suite. Un éditorial publié dans un quotidien de Montréal attaquait assez rudement le recours à cette procédure en invoquant les arguments suivants :

Il serait trop facile pour des procureurs incompétents de voiler la minceur de leurs preuves en renvoyant des causes aux calendes grecques. Il serait trop facile pour des politiciens de suspendre des procédures intentées contre des adversaires, d'accrocher au-dessus de leur tête une épée de Damoclès et ainsi, au mépris des lois, de substituer aux jugements des tribunaux un stigmate de soupçon perpétuel ${ }^{11}$.

\section{Le tribunal}

Au Canada, comme dans les autres pays du monde occidental, le fonctionnement des tribunaux est régi par un certain

11. J.C. Leclerc, Le Devoir, 30 août 1971. 
nombre de principes fondamentaux : la séparation des pouvoirs législatif, exécutif et judiciaire, qui assure théoriquement l'indépendance de ce dernier; la présomption d'innocence; le droit à une défense pleine et entière; celui d'être jugé par ses pairs; une certaine rapidité dans l'examen des causes. En temps «normal » et lorsqu'il s'agit des infractions «traditionnelles», ces principes sont souvent violés ou enfreints. Ils le furent d'une façon beaucoup plus flagrante à l'occasion des procès felquistes. Examinons-les brièvement, en consacrant une attention particulière au problème de l'outrage au tribunal.

\section{Le principe de la séparation des pouvoirs :}

L'existence et la correcte application de ce principe garantit, en théorie, l'indépendance de la magistrature face au pouvoir législatif et surtout au pouvoir exécutif, ainsi que l'impartialité de la justice.

Lors des procès felquistes, certains accusés ont remis en question la validité de ce principe. Paul Rose, par exemple, récusa dès le départ la juridiction de la cour devant laquelle il comparaissait, symbole d'un pouvoir établi qu'il fallait combattre. Voici done un acteur qui refusa de jouer les règles du jeu; voici encore l'existence d'un conflit de valeurs menant à une rupture inévitable, à des situations à ce point exceptionnelles qu'elles poussèrent un juge à déclarer : "il va falloir faire preuve d'imagination ».

Si les demandes de Paul Rose, basées essentiellement sur des arguments politiques (situation colonialiste, capitalisme monopolistique, etc.) semblaient hors de propos, celles invoquées par Vallières, Gagnon, Chartrand, Lemieux et Larue-Langlois à l'occasion de leur procès pour conspiration séditieuse pouvaient soulever des doutes sur l'impartialité du tribunal et méritaient d'être prises en considération. En effet, les cinq accusés demandaient la récusation du juge Ouimet pour les raisons suivantes : avoir déjà condamné Michel Chartrand pour outrage au tribunal ; avoir refusé un cautionnement à Vallières, Gagnon et Lemieux, sous prétexte «qu'ils représe:ataient un danger pour la société 》, ce qui constituait en quelque sorte une présomption de culpabilité à leur égard. Les anciennes opinions fédéralistes du juge, ainsi que son option constitutionnelle étaient évaluées comme remettant en cause l'impartialité du magistrat. Le rejet de ces 
demandes méritait une meilleure justification que celle, strictement juridique (l'inexistence d'un précédent judiciaire concernant la récusation d'un juge de la Cour supérieure, étant donné que le jury est le maître absolu des faits), fournie par le tribunal qui les entendit.

Ces exemples aident à mieux situer, bien que de façon indirecte, le problème de l'indépendance de la magistrature. Dans le même ordre d'idées, lorsque Pierre Vallières s'adressait au juge Ouimet dans les termes suivants :

Mais, monsieur le juge Ouimet, l'impression que j'ai c'est que je ne me trouve pas devant une Cour mais devant un parti politique et ceux qui me jugent aujourd'hui, c'est les Libéraux, les membres du Parti libéral ${ }^{12}$.

il soulevait la question de la nomination des juges. Au Québec, la politisation des postes de juge est un fait connu du grand public ${ }^{13}$. Certains travaux de M. Guy Bouthillier ont démontré que 40 des 74 juges ayant siégé à la Cour c'appel du Québec avaient, avant d'accéder à la magistrature, exercé des fonctions politiques officielles. Ces activités politiques avaient représenté, pour la plupart des juges, bien plus qu'une simple péripétie dans leur carrière d'avocat, la durée moyenne des mandats parlementaires ayant été, en effet, établie à 11,6 ans ${ }^{14}$.

Il ne suffit pas qu'il y ait justice ; il doit y avoir également apparence de justice. C'est pourquoi, malgré le fait que certains juges ont finalement rendu des décisions favorables aux felquistes, ceux-ci avaient raison d'insister sur \& ce conflit d'intérêt entre une justice honnêtement rendue et le désir de favoriser un régime auquel tous les antécédents de ces juges les reliaient ${ }^{15}$.

D'autres exemples montrent, d'une façon plus évidente, l'ingérence de l'exécutif dans le processus judiciaire. Tel est le cas de la déclaration faite le 10 octobre 1970 par le ministre de la Justice du Québec, au cours de laquelle M. Choquette promettait aux ravisseurs de Cross, s'ils décidaient de se rendre,

12. Le Procès des cinq, Montréal, Editions Libération, 1971, p. 49.

13. Annexe 4 de La Société face au crime, Commission d'enquête sur l'administration de la justice en matière criminelle et pénale au Québec, Gouvernement du Québec, 1969, p. 65-66.

14. Matériaux pour une analyse politique des juges de la Cour d'appel », Thémis, 1973, no 3, p. 573.

15. Marc Laurendeau, op. cit., note 1, p. 117. Il est à remarquer que les dernières formules concernant la nomination des juges sont susceptibles de dépolitiser considérablement la fonction judiciaire. 
qu'ils bénéficieraient devant les tribunaux « de toute la clémence qu'ils pourront exercer » en prenant acte de tout geste humanitaire qu'ils pourraient poser en vue d'épargner la vie du diplomate britannique. Tel est également le cas des discussions effectuées le 16 décembre de la même année au Conseil des ministres du Québec et de la décision de refuser tout cautionnement aux personnes impliquées dans les deux enlèvements, ainsi qu'à MM. Vallières, Gagnon, Chartrand, Lemieux et Larue-Langlois ${ }^{16}$.

2. La présomption d'innocence :

Certaines violations à cet autre principe fondamental ont déjà été indiquées dans les sections précédentes (rétroactivité de la loi, renversement du fardeau de la preuve, détention incomunicado, refus du cautionnement, etc.).

C'est cependant l'énorme publicité donnée aux événements d'octobre qui a soumis à rude épreuve ce principe. Lors du procès de Paul Rose pour le meurtre de Pierre Laporte, le procureur de la Couronne lui-même reconnaissait la grande publicité faite par les media d'information depuis l'arrestation de l'inculpé, qui était qualifié d'assassin avant même d'avoir comparu devant un tribunal, ainsi que la contribution de la presse dans la formation d'une opinion chez les persones qui seraient appelées plus tard à faire partie du jury. Il convient d'y ajouter la publicité accordée à la déclaration non signée, attribuée par la police à Francis Simard et présentée à l'enquête du Coroner sur la mort de Pierre Laporte, où elle avait été lue publiquement. La publicité des procédures pénales constitue, en principe, une importante garantie pour une saine administration de la justice; les excès auxquels elle peut mener soulignent l'opportunité d'en limiter la portée ainsi que la nécessité de repenser complètement ce principe. Dans des cas semblables à celui que nous rapportons, et lorsque l'atmosphère du pays est troublée, une publicité mal orientée risque de causer des torts irréparables aux accusés.

3. Le droit à une défense pleine et entière :

Une publicité intempestive, le renversement du fardeau de la preuve et la détention incomunicado pendant un long délai

16. A la suite de l'arrestation des frères Rose et de Simard, le ministre de la Justice « restituera 》 aux juges leur pouvoir traditionnel d'accorder ou de refuser des cautionnements. 
constituent autant d'entorses à cet autre principe fondamental du droit pénal. Ce sont cependant l'absence d'avocat et l'expulsion de l'accusé de la salle d'audience qui ont compté parmi les éléments les plus frappants et critiquables des procès felquistes.

Les procès pour meurtre et enlèvement subis par Paul Rose illustrent bien les irrégularités commises en ce qui a trait à ce droit fondamental, ainsi que les dilemmes auxquels a dû faire face l'administration de la justice québécoise. L'inculpé avait demandé, en effet, dès le début de son procès, d'être défendu par Me Lemieux, incarcéré à ce moment-là. Le président du tribunal ne pouvant rien faire pour satisfaire à la demande de Paul Rose, celui-ci accusa la Cour de le priver du droit à une défense pleine et entière, refusa de choisir un autre avocat et décida de se défendre seul.

Plus lourde de conséquences fut la décision de certains juges de se prévaloir du paragraphe 2(a) de l'article 557 du Code pénal pour expulser de la salle d'audience divers accusés indociles. Ce fut notamment le cas de Paul Rose lors de ses deux procès pour meurtre et enlèvement. Reconnu coupable de meurtre et condamné à l'emprisonnement à perpétuité, Rose demanda à la Cour d'appel d'annuler ce verdict et d'ordonner un nouveau procès, invoquant, parmi d'autres motifs, l'impossibilité dans laquelle il s'ćtait trouvé de présenter une défense pleine et entière à la suite de son expulsion, compte tenu notamment du fait qu'il se défendait seul. En voici quelques raisons : ayant été expulsé avant que le choix des jurés ne soit terminé, il n'avait pas pu exercer son droit de récuser péremptoirement certains candidats et de leur poser des questions. Il n'avait pas eu non plus le droit de contre-interroger les témoins de la Couronne; le juge avait limité son droit de présenter des témoins et de les rencontrer avant leur témoignage et il avait mis fin au plaidoyer de l'accusé devant le jury avant qu'il ne l'ait terminé. Par ailleurs, lors de son procès pour enlèvement, Paul Rose, qui continuait à se défendre seul, avait été de nouveau expulsé de la Cour, et a été absent par conséquent au moment du verdict (un précédent dans les annales judiciaires canadiennes). Ce qui fut le plus extraordinaire et le plus inquiétant dans ce dernier procès, ce fut l'interprétation que le juge Legault fit de l'article 557 du Code pénal. Le magistrat avait expulsé définitivement Paul Rose de la Cour parce que l'accusé ne s'était pas levé lors de 
l'entrée du juge dans la salle d'audience. Outre le fait que, depuis le début de son procès, Paul Rose ne s'était jamais plié à cet usage, on peut se demander si le refus d'accueillir le magistrat en se levant constitue une interruption des procédures telle qu'on ne puisse les continuer en la présence de l'accusé.

De toute évidence, l'intention des inculpés d'octobre était de montrer les contradictions internes du système de justice et de situer les débats sur le terrain strictement politique qu'ils avaient choisi. Dans une lettre de Vallières à Lanue-Langlois, qui sera versée au dossier, celui-là écrivait :

Vous aviez tous un peu de misère à comprendre cette obstination à nous défendre seuls. En réalité, nous ne faisons qu'être conséquents avec les principes qui animent notre action depuis notre adhésion irrévocable au FLQ. Les procès sont pour nous, avant tout, des occasions d'introduire ouvertement dans le s sanctuaire * hypocrite des tribunaux la lutte des classes. En nous défendant nous-mêmes, nous forçons le juge et la poursuite à nous affronter directement, sans l'intermédiaire ou plutôt l'écran d'un avocat bourgeois qui, consciemment ou inconsciemment, recherche toujours un terrain d'entente avec l'arbitraire institutionnalisé qu'on appelle l'administration de la justice. C'est cet arbitraire qu'il faut dévoiler par notre présence et notre intransigeance... Il n'y a qu'une chose à faire : politiser au maximum toute l'affaire, sans cependant se faire d'illusions ; rechercher constamment le profit politique, sans se préoccuper de la « justice ».

Ainsi, les procès felquistes ont été dans une grande mesure un camp d'entraînement à la lutte judiciaire contre le régime actuel, ses lois et ses institutions. La justice québécoise a souvent joué le jeu souhaité par ses adversaires et s'est fortement discréditée. Si elle avait fait preuve d'un peu d'imagination, elle aurait pu, lors du procès de Paul Rose ayant abouti à l'exclusion de l'inculpé, plutôt que de risquer d'enfreindre un principe fondamental du droit, utiliser d'autres alternatives. Garder, par exemple, l'accusé en détention et retarder le procès jusqu'à ce que l'inculpé ait fait preuve de dispositions plus positives, ou encore lui permettre de suivre les procédures dans une autre salle à travers un circuit fermé de télévision, etc.

Le droit à une défense pleine et entière soulève finalement le problème de la rapidité ou de la lenteur de la justice pénale et de ses conséquences. Là encore, le système judiciaire a eu à 
faire face à des dilemmes d'envergure. En effet, si les felquistes avaient été jugés trop rapidement, on aurait critiqué cette célérité qui empêchait la préparation d'une défense convenable et était susceptible de nuire aux accusés en raison du climat de passion et d'intérêt que leurs actes avaient pu déclencher dans la population. Si, par contre, ils avaient utilisé à leur avantage les possibilités très étendues de recours que leur ouvrait le système au chapitre de la procédure, la justice aurait alors été accusée de lenteur.

En procédant à une révision minutieuse des procès d'octobre, on peut affirmer qu'une partie importante des délais survenus furent causés, non pas par la Couronne ou la magistrature, mais par les accusés eux-mêmes, qui ont présenté de multiples requêtes et motions et demandé le témoignage d'innombrables personnes (y compris les plus hautes autorités politiques du pays). Ces délais, ainsi que l'importance accordée à ces procès, ont eu comme conséquence d'accaparer pendant des mois plusieurs divisions des assises, de faire reporter à des dates ultérieures des dizaines de procès « ordinaires 》 et de retenir en prison ou en attente de jugement un nombre considérable d'inculpés.

4. Les procès felquistes ont finalement remis en question les procédures appliquées à l'occasion de l'enquête du coroner et, en particulier, la publication d'une confession attribuée à un des suspects mais non signée, ainsi que le rôle du jury. En ce qui concerne cette dernière institution, grâce à laquelle peut s'effectuer une certaine démocratisation de la justice, outre diverses irrégularités commises à l'occasion de sa constitution (lors du procès pour meurtre intenté contre Paul Rose, un des candidatsjurés, après s'être déclaré partial, avait été accepté par la Cour), on lui a surtout reproché les critères devant servir à la sélection des candidats et, partant, son manque de représentativité de la population, en particulier de la population féminine ${ }^{17}$. Dans une de ses requêtes demandant la récusation du tableau des jurés, Paul Rose soulignait le fait que ses pairs étaient e des travailleurs, des gars de Saint-Henri, des gars du peuple québécois et non pas des ingénieurs et des hommes d'affaires ». Il dénonçait également la discrimination créée par la loi en éliminant les femmes et les personnes n'ayant pas une valeur immobilière de $\$ 4000$ ou une évaluation locative de $\$ 500$ en disant :

17. Au Québec, les femmes ne sont admises au jury que depuis 1971. 
Vous éliminez $50 \%$ de la population du Québec pour former un tableau de jurés et vous gardez ceux qui ne sont pas mes vrais pairs. $\mathrm{Si}$ Ie gouvernement voulait se montrer un peu honnête, il me trouverait des jurés jeunes, des étudiants, des travailleurs de chez nous.

\section{L'outrage au tribunal :}

Depuis le début des procédures judiciaires relatives aux événements d'octobre, une vingtaine de personnes furent condamnées pour plus de 60 outrages au tribunal à un total d'environ 12 ans de prison. Les condamnations les plus lourdes furent prononcées contre Paul Rose (38 mois de prison pour 19 outrages commis à l'occasion du procès du felquiste Claude Morancy, en octobre 1971 et 7 autres condamnations pendant son propre procès), le felquiste Jean Boisjoly (15 mois pour 5 outrages, en janvier de la même année) et le syndicaliste Michel Chartrand (12 mois pour 4 outrages, également en janvier 1971).

Plusieurs motifs ont pu, en principe, justifier l'application de \&ce pouvoir que les juges ne devraient exercer qu'avec angoisse ${ }^{18}$ ». Parmi les plus importants : a) le refus de témoigner, soit lors de l'enquête du coroner spécial sur la mort de Pierre Laporte (ce fut le cas de Lise Rose), soit à l'occasion des procès d'assises (Jacques Rose, Bernard Lortie, Francis Simard et Lise Balcer refuseront de témoigner contre Paul Rose ; celui-ci fera de même lors du procès de Claude Morancy); et b) les insultes et injures proférées en Cour contre certains juges ou, en général, contre l'actuel système juridico-politique (ce fut le cas de la plupart des accusés et, en particulier, les dénonciations véhémentes de certaines femmes contre l'absence de l'élément féminin dans le jury).

L'outrage au tribunal est une procédure d'exception qui, selon les historiens, remonte à la Chambre étoilée anglaise, Cour qui au XVII ${ }^{e}$ siècle permettait de régler rapidement certaines causes ayant trait aux fraudes, aux parjures, aux émeutes, aux conspirations et aux libelles diffamatoires. Cette Chambre fut dissoute en 1640 par le Parlement britannique, qui la considérait par trop expéditive. En 1899, le Conseil privé anglais se prononçait comme suit sur cette procédure :

Il peut y avoir mépris de cour par la publication de choses offensantes envers la Cour, soit après sa décision, soit pen-

18. Titre d'un éditorial de Claude Ryan, Le Devoir, 11 janvier 1971. 
dant le procès qu'elle instruit. En Angleterre, de tels mépris de cour sont tombés en désuétude, mais dans les petites colonies où la population de couleur est en majorité, il peut être utile dans les cas appropriés d'y recourir ${ }^{19}$.

Le Canada, qui a conservé dans son Code pénal cette procédure d'exception, serait-il encore une de ces colonies ? Quoi qu'il en soit, la Cour d'appel du Québec considérait, en décembre 1970 , que «ce pouvoir de condamnation pour outrage au tribunal commis en présence de la cour est un pouvoir arbitraire qui doit être exercé avec précaution et discrétion».

Les condamnations de cette nature pendant, ou à l'occasion des procès d'octobre, ont été d'une extrême sévérité. Certes, il semblerait à première vue que cette procédure puisse être un outil idéal pour faire respecter l'ordre dans une cour de justice et pour défendre l'honneur et la dignité de la magistrature. On peut, par ailleurs, affirmer que les procès felquistes ont constitué l'une des plus rudes épreuves de sagesse et de force morale qu'aient jamais subies nos tribunaux. Une telle sévérité était-elle, néanmoins, justifiée ? Un juge que l'on invective et que l'on insulte alors qu'il préside une cour peut-il en outre - et doit-il - condamner lui-même et sur-le-champ l'auteur de ces insultes ? Que penser d'un magistrat qui, sans s'imposer une période raisonnable de réflexion, décide «à vif »d'envoyer à l'ombre pour 38 mois, sous 19 chefs successifs d'outrage au tribunal, un accusé qui, dans un laps de temps de quelques minutes, lui a lancé autant d'insultes?

Le 20 janvier 1971, la Cour suprême des États-Unis décidait à l'unanimité qu'un juge qui a été insulté en cour peut imposer sur-le-champ une condamnation pour outrage au tribunal mais que, s'il attend à la fin du procès, il doit laisser le prononcé de la sentence à un autre magistrat. Le plus haut tribunal américain estimait que «si un juge ne doit pas perdre le contrôle d'un procès, il doit néanmoins se conduire de façon à ne pas donner l'impression qu'il veut se venger personnellement »; ainsi, lorsque des abus de langage sont dirigés contre la personne même du juge, celui-ci devrait demander à un collègue de porter un jugement à sa place.

Il reste encore le problème du recours à l'emprisonnement en tant que moyen d'assurer l'ordre et le décorum de la cour.

19. Alain Zolty, La Presse, 2 février 1971. 
Dans les cas qui nous occupent, d'autres mesures auraient pu être envisagées : l'expulsion du tribunal et la mise à l'écart dans une salle où, grâce aux techniques nouvelles, l'inculpé récalcitrant aurait pu suivre chaque étape de la procédure.

Les aspects évoqués sont d'autant plus graves que, bien qu'une personne condamnée pour outrage au tribunal commis en présence du juge soit autorisée à interjeter appel de la peine imposée, elle ne le peut pas lorsqu'il s'agit de la condamnation elle-même.

Certains juristes ont songé à contester la validité constitutionnelle des dispositions du Code pénal concernant le mépris de cour. En effet, la procédure selon laquelle une personne peut être déclarée sommairement coupable par le même juge qui a été insulté entre en conflit avec trois principes fondamentaux de notre justice. Le principe qui établit que nul ne peut être juge dans sa propre cause, celui selon lequel il faut toujours entendre la partie adverse avant une condamnation, et celui enfin selon lequel toute personne est considérée innocente jusqu'à la preuve indiscutable de sa culpabilité. Cette disposition pénale entre aussi en conflit avec les deux premiers articles de la Déclaration canadienne des droits, où l'on prévoit qu'aucune loi « ne doit s'interpréter comme privant une personne du droit à une audition impartiale de sa cause $\triangleright$; or en l'occurrence, le juge est à la fois juge et partie.

Un appareil judiciaire au-delà de tout soupçon de partialité, d'incompétence et d'ingérence politique est une des assises indispensables à l'existence d'une société démocratique.

\section{E. Le système correctionnel}

Comme cela a été le cas pour les autres secteurs du système de justice pénale, un certain nombre d'anomalies ont pu être décelées, à l'égard des condamnés felquistes, en ce qui concerne l'appareil correctionnel. Résumons-les brièvement.

Sur le plan de l'emprisonnement, les détenus felquistes ont formulé de nombreuses critiques au sujet des points suivants : mauvais traitements, transferts d'institution sans raison valable ni avertissement, des conditions de détention rigoureuses (en particulier, trop long séjour dans des institutions à sécurité maxi- 
male), ségrégation sans motifs, dispersion systématique des condamnés dans des établissements différents, traitement général différent de celui appliqué aux détenus de droit commun, interdiction (pour des raisons de sécurité) de participer aux activités communautaires. Les détenus felquistes ont été considérés, pour des fins pénitentiaires, comme des « cas spéciaux 》, relevant de l'autorité absolue d'un comité spécial composé d'ex-directeurs à la sécurité carcérale, de représentants de la GRC et de hauts fonctionnaires fédéraux.

En ce qui a trait à la libération conditionnelle, elle a été accordée avec beaucoup de facilité dans certains cas, mais refusée systématiquement dans d'autres (Paul Rose, Lortie, Simard, Geoffroy), malgré le fait que tous ces détenus étaient éligibles depuis quelques années soit à une libération conditionnelle de jour, soit même à une libération complète.

\section{CONCLUSION}

Depuis environ une quinzaine d'années, les divers secteurs de l'administration de la justice pénale sont accusés d'être incapables de remplir adéquatement la mission pour laquelle ils furent creés. Ceci semble d'autant plus vrai que ces organismes ont quelquefois à faire face à des situations inédites.

Tel a été le cas des institutions québécoises ayant eu à affronter les séquelles juridiques et judiciaires de la crise d'octobre 1970. La guérilla entreprise par plusieurs inculpés felquistes réussit, dans l'ensemble, à montrer les déficiences de la loi, à dénoncer certaines pratiques policières et pénitentiaires, à mettre en mauvaise posture la poursuite qui les accusait, à pousser les tribunaux dans des impasses juridiques et à démontrer le caractère inadéquat de certaines procédures. Elle a réussi également à ébranler les fondements mêmes des mécanismes officiels de contrôle.

Le dialogue de sourds qui s'est engagé, à travers les médias, entre le gouvernement et le FLQ, fut transposé devant les tribunaux, mettant non seulement l'appareil judiciaire mais également l'ensemble de l'administration de la justice, devant des défis nouveaux.

Alors que policiers, procureurs et juges, réagissaient comme s'ils avaient à faire face à des délinquants « ordinaires », mon- 
trant de la sorte leur naïveté, les accusés d'octobre, peu inquiets de leur sort personnel, exploitèrent à fond les contradictions existant au sein de la législation en vigueur et des institutions qui les incarnaient. Dans ces causes à caractère inévitablement politique, les règles du jeu ne furent pas utilisées pour des fins individuelles - condamnation ou acquittement - mais pour des objectifs bien différents : contester la légitimité des institutions politiques et judiciaires.

Aurait-il fallu, dans ces conditions, - et faudrait-il, si des situations semblables survenaient de nouveau - reconnaître un statut juridique spécial pour ceux qui commettent des « délits politiques »? Il est dangereux de créer deux systèmes parallèles de justice pour des infractions matériellement identiques. L'existence d'une «justice politique » risque d'ouvrir toute grande la porte aux procès d'intention et à l'arbitraire des autorités. L'histoire récente tend à prouver que les tribunaux de cette espèce sont le plus souvent des instruments de répression au service d'une idéologie politique privilégiée.

Malgré les nombreuses critiques dont il a été - et est encore - l'objet, le système de justice actuel est fondé sur un certain nombre de principes fondamentaux qu'on ne saurait rejeter d'un simple revers de la main. Une révision en profondeur s'impose néanmoins, qui devrait affecter l'ensemble du système. À cet égard, les événements d'octobre et leurs suites policières, judiciaires et pénitentiaires auront servi à souligner leurs principales lacunes et défaillances.

\section{BIBLIOGRAPHIE}

BAUDOUIN, J.-L. ct al. (1970) : Teirorisme et justice, Montréal, Éditions du Jour.

BELLAVANCE, M. et GILBERT, M. (1971) : L'Opinion publique et la crise d'octobre, Montréal, Éditions du Jour.

CHARTRAND, M. et al. (1971) : Le Procès des cinq, Ottawa, Éditions Libération.

COMITÉ SUR LA SÉCURITÉ NATIONALE (1978) : La Police secrète au Québec, Montréal, Éditions Québec-Amérique.

DION, R. (1979) : Les Crimes de la police montée, Laval, Éditions coopératives, Albert Saint-Martin. 
HAGGART, R. et GOLDEN, A.E. (1971) : Octobre 70 un an... après, Montréal, Hurtubise - HMH.

LAURENDEAU, M. (1974) : Les Québécois violents, 2e édition, Montréal, Boréal Express.

MORF, G. (1970) : Le Terrorisme québécois, Montréal, Editions de l'Homme.

PELLETIER, G. (1971) : La Crise d'octobre, Montréal, Éditions du Jour. RYAN, C. éd. (1971) : Le Devoir et la crise d'octobre, Montréal, Leméac. TRAIT, J.-C. (1970) : FLQ 70 : Offensive d'automne, Montréal, Editions de l'Homme.

VALLIÈRES, P. (1977) : L'exécution de Pierre Laporte, Montréal, Hurtubise - HMH. 